\title{
An M2e-based multiple antigenic peptide vaccine protects mice from lethal challenge with divergent H5N1 influenza viruses
}

Guangyu Zhao ${ }^{1,2}$, Yongping Lin², Lanying Du ${ }^{3}$, Jie Guan', Shihui Sun ${ }^{1}$, Hongyan Sui ${ }^{2}$, Zhihua Kou', Chris CS Chan² , Yan Guo', Shibo Jiang ${ }^{3}$, Bo-Jian Zheng ${ }^{2^{*}}$, Yusen Zhou ${ }^{1^{*}}$

\begin{abstract}
Background: A growing concern has raised regarding the pandemic potential of the highly pathogenic avian influenza (HPAl) H5N1 viruses. Consequently, there is an urgent need to develop an effective and safe vaccine against the divergent H5N1 influenza viruses. In the present study, we designed a tetra-branched multiple antigenic peptide (MAP)-based vaccine, designated M2e-MAP, which contains the sequence overlapping the highly conserved extracellular domain of matrix protein 2 (M2e) of a HPAI H5N1 virus, and investigated its immune responses and cross-protection against different clades of $\mathrm{H} 5 \mathrm{~N} 1$ viruses.

Results: Our results showed that M2e-MAP vaccine induced strong M2e-specific lgG antibody responses following 3-dose immunization of mice with M2e-MAP in the presence of Freunds' or aluminium (alum) adjuvant. M2e-MAP vaccination limited viral replication and attenuated histopathological damage in the challenged mouse lungs. The M2e-MAP-based vaccine protected immunized mice against both clade1: VN/1194 and clade2.3.4: SZ/406H H5N1 virus challenge, being able to counteract weight lost and elevate survival rate following lethal challenge of H5N1 viruses.
\end{abstract}

Conclusions: These results suggest that M2e-MAP presenting M2e of H5N1 virus has a great potential to be developed into an effective subunit vaccine for the prevention of infection by a broad spectrum of HPAI H5N1 viruses.

\section{Background}

The re-emergence of H5N1 highly pathogenic avian influenza (HPAI) in 2003 has caused 262 fatal cases among a total of 442 infected individuals [1]. Therefore, there is an urgent need to develop safe and effective antiviral strategies for the prevention of any future pandemic of H5N1 HPAI [2,3], among which vaccination is still the most effective means to prevent influenza A virus infection. Due to current vaccine technologies facing annual problems with vaccine-strain matching, some conserved antigens of influenza A virus become promising target for the development of influenza vaccines with broad cross-protection.

\footnotetext{
* Correspondence: bzheng@hkucc.hku.hk; yszhou@nic.bmi.ac.cn 'State Key Laboratory of Pathogen and Biosecurity, Beijing Institute of Microbiology and Epidemiology, Beijing 100071, China

${ }^{2}$ Department of Microbiology, The University of Hong Kong, Hong Kong,
} China

(c) 2010 Zhao et al; licensee BioMed Central Ltd. This is an Open Access article distributed under the terms of the Creative Commons Attribution License (http://creativecommons.org/licenses/by/2.0), which permits unrestricted use, distribution, and reproduction in any medium, provided the original work is properly cited.
In comparison with other surface proteins of H5N1 viruses, matrix protein 2 (M2) is the most conserved. The native M2 protein exists as a homotetramer formed by two disulfide linked dimers, with each monomer consisting of 97 amino acids $[4,5]$. The 24-amino-acid extracellular domain of M2 protein (M2e) is remarkably conserved across influenza A subtypes [6]. Passively transferred anti-M2 monoclonal antibodies (mAbs) accelerated lung viral clearance [7], and mAbs recognizing the $\mathrm{N}$-terminus highly conserved epitope in M2e protected mice from lethal influenza $\mathrm{A}$ virus challenge [8], implying that M2, in particular M2e, may serve as an attractive vaccine target. Currently, the rapid evolution of $\mathrm{H} 5 \mathrm{~N} 1$ virus and the co-circulation of multiple antigenic variants in multiple regions determine that development of $\mathrm{H} 5 \mathrm{~N} 1$ vaccine with cross-protection against divergent $\mathrm{H} 5 \mathrm{~N} 1$ viruses would be inevitable. Although a number of M2e-based vaccines have been 
reported to provide broad-spectrum protection against ordinary human influenza virus infection [9-13], the cross-protective effect to divergent $\mathrm{H} 5 \mathrm{~N} 1$ viruses was undocumented.

In the present study, we designed and synthesized a tetra-branched multiple antigenic peptide (MAP) derived from the M2e sequence of H5N1 virus VN/1194 strain, denoted as M2e-MAP, with an aim to develop a M2e-based vaccine for induction of M2e-specific immune responses and cross-protection of the vaccinated animals against lethal challenge of divergent H5N1 virus strains.

\section{Results}

M2e-MAP immunization induced potent M2e-specific antibody responses

To evaluate humoral immune responses potentially induced by M2e-MAP, mice were vaccinated with $10 \mu \mathrm{g}$ of M2e-MAP plus Freund's or aluminium (alum) adjuvant as described in Methods, and M2e-specific IgG antibodies were detected in mouse serum samples by ELISA. As shown in Figure 1, M2e-MAP induced strong M2e-specific IgG antibody responses, with the highest titer reaching $1: 10^{5}$ and $1: 10^{4}$ for M2e-MAP+FCA/FIA and M2e-MAP+alum, respectively, at 10 days post last boost vaccination. In contrast, only background level of antibody responses was detected in the mice receiving adjuvant alone.
M2e-MAP vaccination limited viral replication and attenuated virus-induced lung pathology

Two phylogenetically distinguished $\mathrm{H} 5 \mathrm{~N} 1$ virus isolates, clade1: VN/1194 and clade2.3.4: SZ/406H were selected to evaluate the protective immunity afforded by $\mathrm{M} 2 \mathrm{e}$ MAP vaccine in vivo. Two weeks after the last boost, mice were challenged with $10 \mathrm{LD}_{50}$ of $\mathrm{H} 5 \mathrm{~N} 1$ virus $\mathrm{VN} /$ 1194 or SZ/406H. Five days post-challenge, lungs were removed from infected mice, and infectious virus titers in the lung tissues were measured to determine the protective effects of M2e-MAP vaccine on viral clearance. Compared with those from the adjuvant control (FCA/ FIA or alum), the virus titers in the lungs of M2e-MAP vaccinated mice were significantly lower after $\mathrm{H} 5 \mathrm{~N} 1$ virus challenge $(P<0.0001)$ (Figure 2$)$, suggesting that M2e-MAP vaccine can induce protective immunity against viral replication in vaccinated mice.

Further examination of the lung tissues of virus-challenged mice revealed dramatic histopathological damage in the pulmonary airways and parenchymal tissues in the adjuvant group, including severe damage of bronchial epithelium with necrosis and desquamation, pulmonary vascular dilatation and congestion, infiltration of prominent number of lymphocytes accompanied by exudates and severe edema, especially around vessels, as well as broadening interstitial spaces or fused alveoli walls with focal hemorrhage (Figure 3A). In contrast, lungs of M2e-MAP-vaccinated mice exhibited less

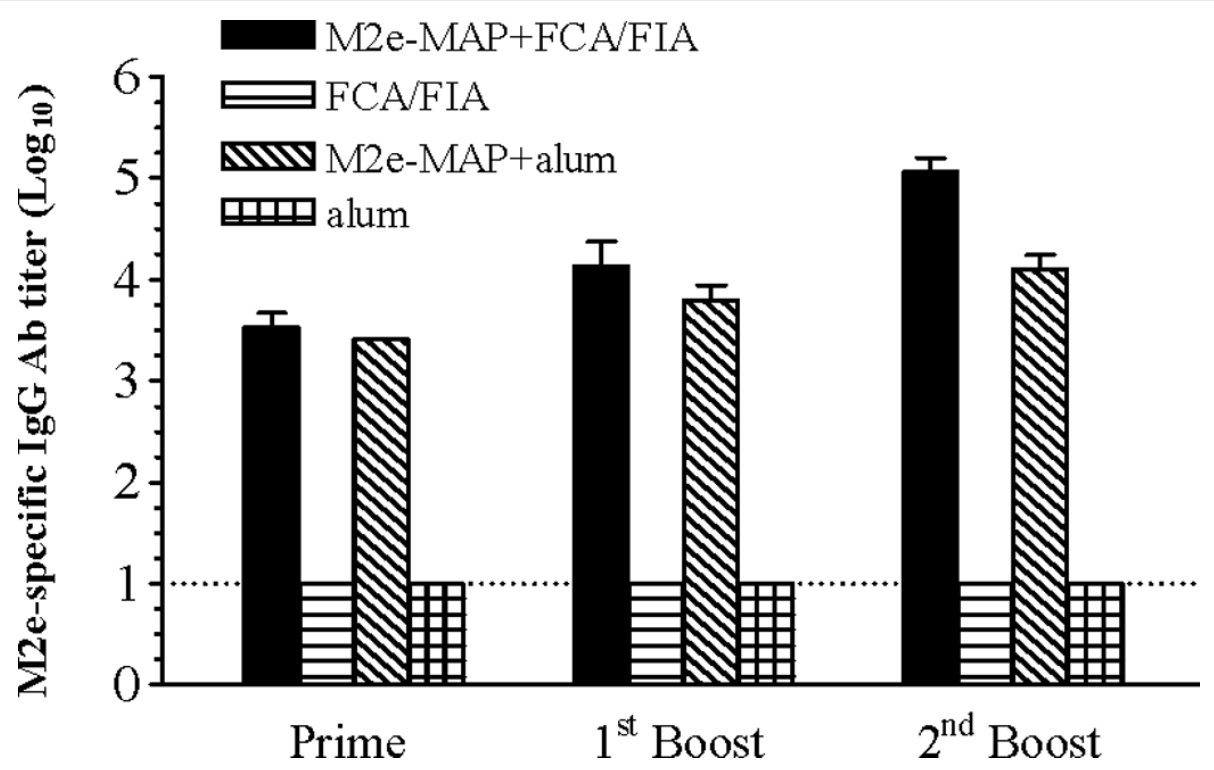

Figure 1 M2e-specific antibody responses induced by M2e-MAP vaccine. Mice were vaccinated with M2e-MAP plus FCA/FIA (s.c.) or alum (i. m.) adjuvant for a total of 3 times. Mice receiving FCA/FIA or alum alone were served as adjuvant controls. Mouse sera were collected preimmunization and 10 days post-each immunization for detection of M2e-specific antibodies by ELISA. The end-point titer of each sample was determined as the highest dilution that yielded an $\mathrm{OD}_{450} \mathrm{~nm}$ value greater than twice that of similarly diluted serum sample collected prevaccination. The data are expressed as geometric mean titer (GMT) \pm standard deviation (SD) of 10 mice per group. The lower limit detection $(1: 10)$ is indicated by a dotted line. Experiments were repeated three times. 


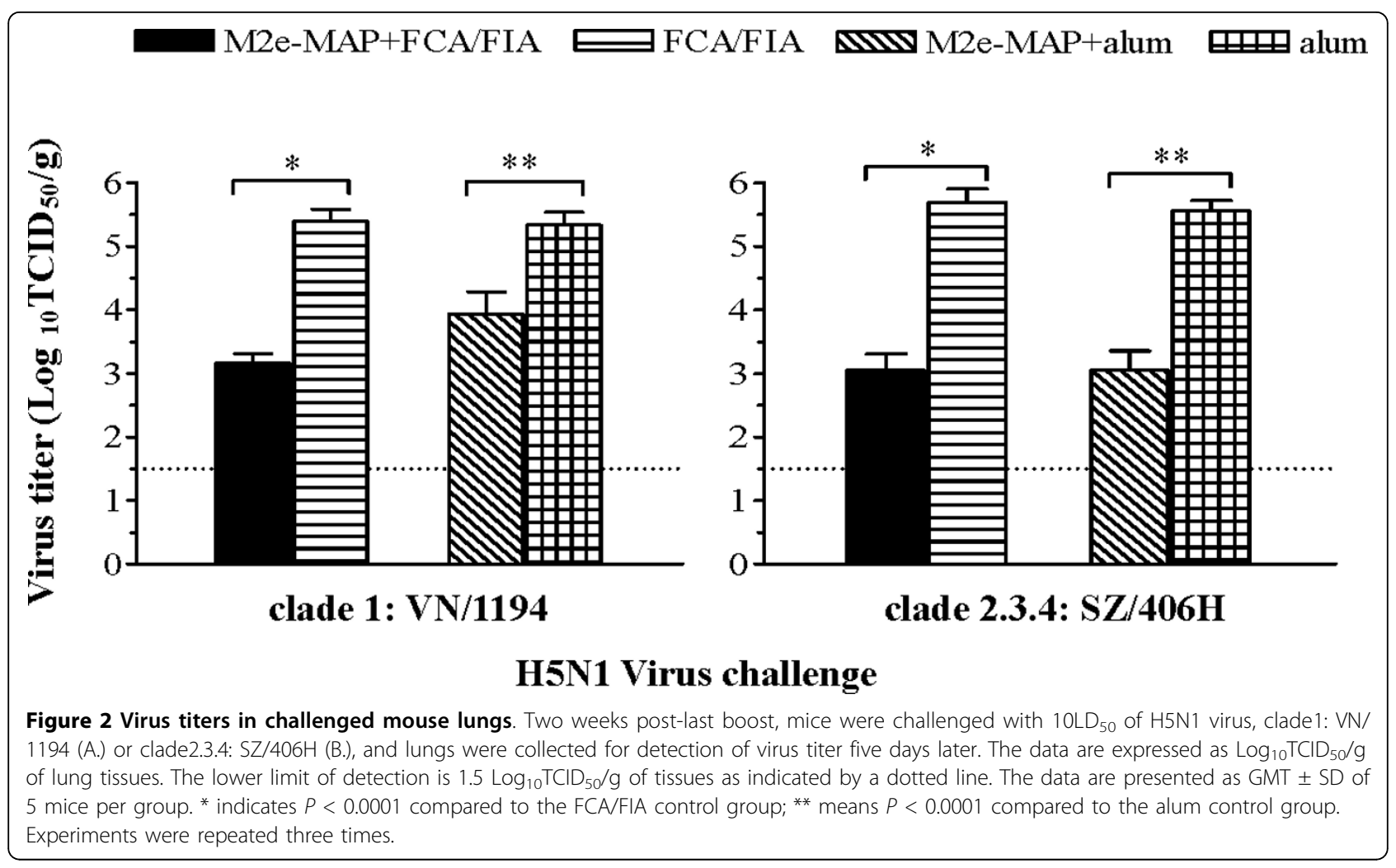

histopathological changes, accompanied by only mild pulmonary interstitial pneumonia and moderate lymphocytic infiltration (Figure 3B). The above data implied that M2e-MAP vaccination may protect the mice against lethal challenge of divergent $\mathrm{H} 5 \mathrm{~N} 1$ viruses through a combination of limiting viral replication in the lungs and attenuating virus-induced lung pathology.

\section{M2e-MAP vaccination elicited cross-protection against} lethal challenge of divergent $\mathrm{H} 5 \mathrm{~N} 1$ viruses

After receiving the lethal dose $\left(10 L_{50}\right)$ of two $H 5 N 1$ virus strains, the M2e-MAP vaccinated mice were further evaluated in terms of cross-protective ability by daily observation of the clinical symptoms, including weight loss and survival rate for two weeks, and then histopathological examination following removal of lung tissues.

From day 4 after VN/1194 and day 3 after SZ/406H virus infection, the adjuvant control mice (FCA/FIA or alum) developed obvious clinical signs, including ruffled fur, hunched posture, rapid breathing, inactivity and paralysis of posterior limb. These clinical signs were either not observed or were delayed for 2-3 days in the M2e-MAP vaccination group. Most M2e-MAP vaccinated mice with clinical signs only exhibited slight or partial piloerection for 2-3 days and then recovered. Moreover, compared to the adjuvant control, M2e-MAP vaccinated mice that did not survive the challenges were observed to have delayed the onset of illness and longer survival days. The observed protection against clinical signs correlated with the changes in body weight. In the adjuvant group, body weight dramatically decreased and even reached a near $25 \%$ severe weight loss after H5N1 virus infection. In contrast, the average body weight in the M2e-MAP vaccination group only slightly decreased (less than 10\%) during 6-10 days after challenge and then steadily increased (Figure 4A).

All control mice receiving FCA/FIA or alum adjuvant alone died from virus challenge, while $70 \%$ to $80 \%$ of the mice vaccinated with M2e-MAP survived the lethal H5N1 virus challenge (Figure 4B), with significantly increased survival rate $(P<0.0001)$. At 14 days postchallenge, lung tissues from surviving mice were removed to evaluate viral replication and histopathological damage. No H5N1 virus was detected in the lungs of surviving mice, and the lung tissues of these mice presented almost normal structures (data not shown). The above data confirmed that M2e-MAP vaccine can afford cross-protection against lethal challenge of divergent $\mathrm{H} 5 \mathrm{~N} 1$ viruses.

\section{Discussion}

A cross-protective vaccine for antigenic variants of H5N1 virus is a very important component in prophylactic strategy against a possible human pandemic. 


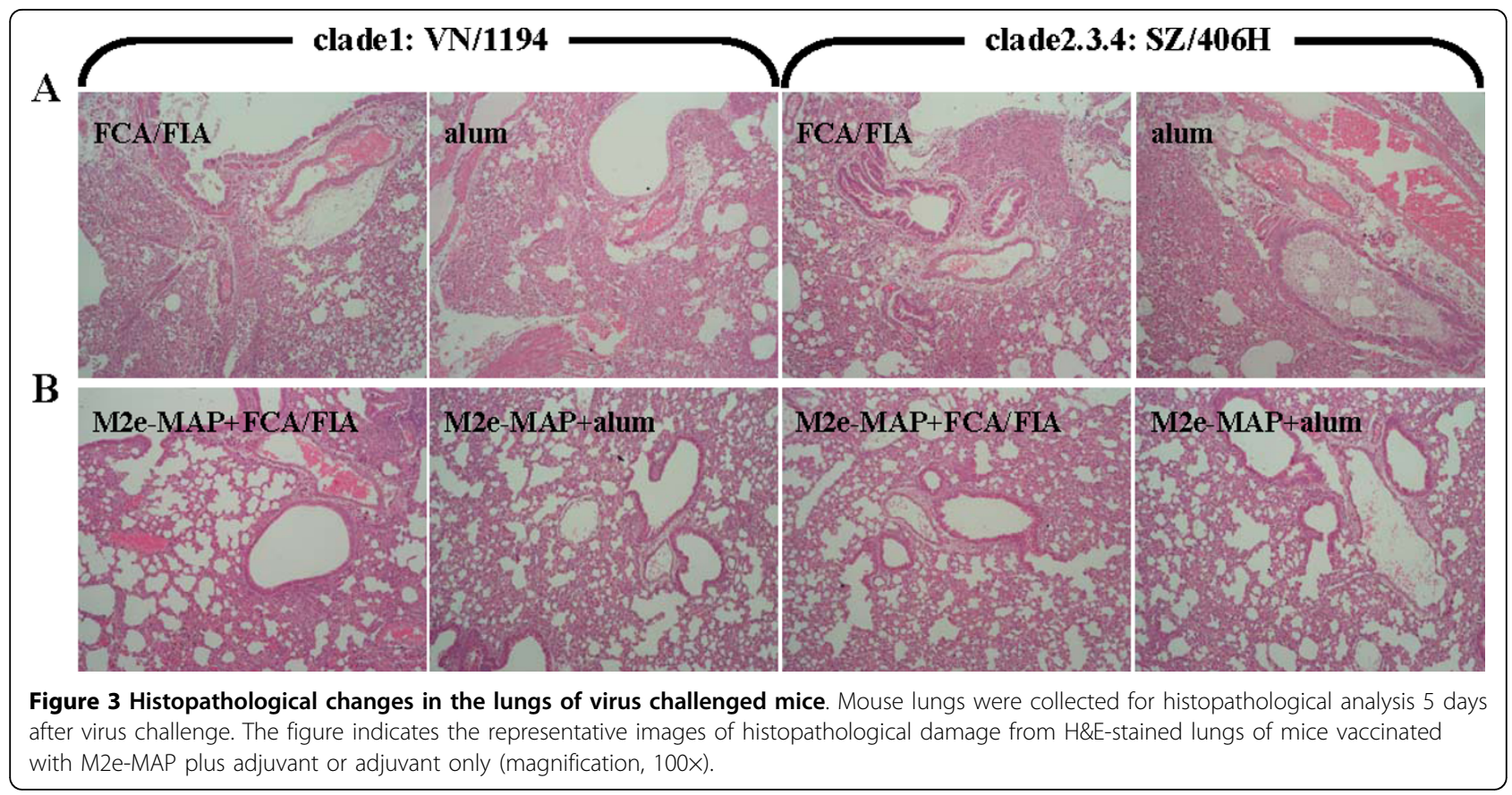

Although the highly conservative M2e of influenza A virus is one of the most promising target for development of universal influenza vaccines, some strategies would be required to improve immunogenicity of vaccines based on M2e containing only 24 amino acid.

The high molar ratio and dense packing of multiple copies of a target antigen in MAP system have been shown to stimulate better immune responses than single-chain peptides [14-16]. Mozdzanowska et al. [17] reported that MAP system presenting human influenza M2e sequence was an effective immunogen, with antiM2e IgG antibodies from mice immunized with M2eMAP binding specifically to M2-expressing cells. However, it is unclear whether M2e-MAP could be used as a vaccine candidate to provide effective protection against HPAI H5N1 virus. Different from human influenza A viruses of $\mathrm{H} 1, \mathrm{H} 2$ or $\mathrm{H} 3, \mathrm{H} 5 \mathrm{~N} 1$ viruses have circulated only in domestic and wild birds so far [18-21]. The $\mathrm{H} 5 \mathrm{~N} 1$ viruses leading to human infections still belong to the avian type [22]. M2e vaccine designed on sequences of human influenza virus $\mathrm{H} 1, \mathrm{H} 2$ or $\mathrm{H} 3$ subtype may not provide the same protection against $\mathrm{H} 5 \mathrm{~N} 1$ virus leading to human infections [11]. Moreover, the 10-20 amino acid region of M2e was consistent with host restriction specificities [23].

In this study, we designed M2e-MAP in tetrabranched form containing 4 copies of sequence overlapping M2e of VN/1194, a HPAI H5N1 strain (Figure 5). High titers of M2e-specific antibody responses could be induced following immunization of M2e-MAP plus Freund's adjuvant, a commonly used adjuvant in animal experiments or alum, a common adjuvant for human vaccines (Figure 1). Although it has been shown that M2e-specific IgG antibodies do not exhibit an ability to directly neutralize virus in vitro, the antiviral effect of M2e-based vaccines was mediated by antibodies to M2e antigen. The mechanism of such antibody mediated antiviral effect could be due to antibody-dependent cellmediated cytotoxicity (ADCC) and/or complementmediated cytotoxicity (CDC) [24,25]. Therefore, the induction of M2e-specific antibody responses was necessary for M2e-based vaccines in the prevention of $\mathrm{H} 5 \mathrm{~N} 1$ virus infection.

Strikingly, M2e-MAP vaccination with Freund's and alum adjuvants conferred cross-protection against a lethal challenge with not only the homologous strain, $\mathrm{VN} / 1194$ in clade1, but also a divergent strain, SZ/406H in clade2.3.4. M2e-MAP vaccination in mice delayed the onset of illness, prolonged survival, alleviated body weight loss, limited viral replication and restricted histopathological damage in lung tissues (Figure 2, Figure 3 and Figure 4). The clade categorization of the VN/1194 and $\mathrm{SZ} / 406 \mathrm{H}$ strains was based on the phylogenetic analysis of the HA gene. The clade2.3.4 viruses seem to have been prevalent in China since late 2005 and were also responsible for human infection in Laos, Malaysia and Vietnam [26,27], which included A/Hunan/2/2009, one of the most recent human isolates from China [28].

Compared with the monomeric M2e peptide-based vaccines, M2e-MAP vaccine could induce stronger protective immunity due to the immune enhancing effect of the T-helper epitope in the vaccine [14]. In terms of the 

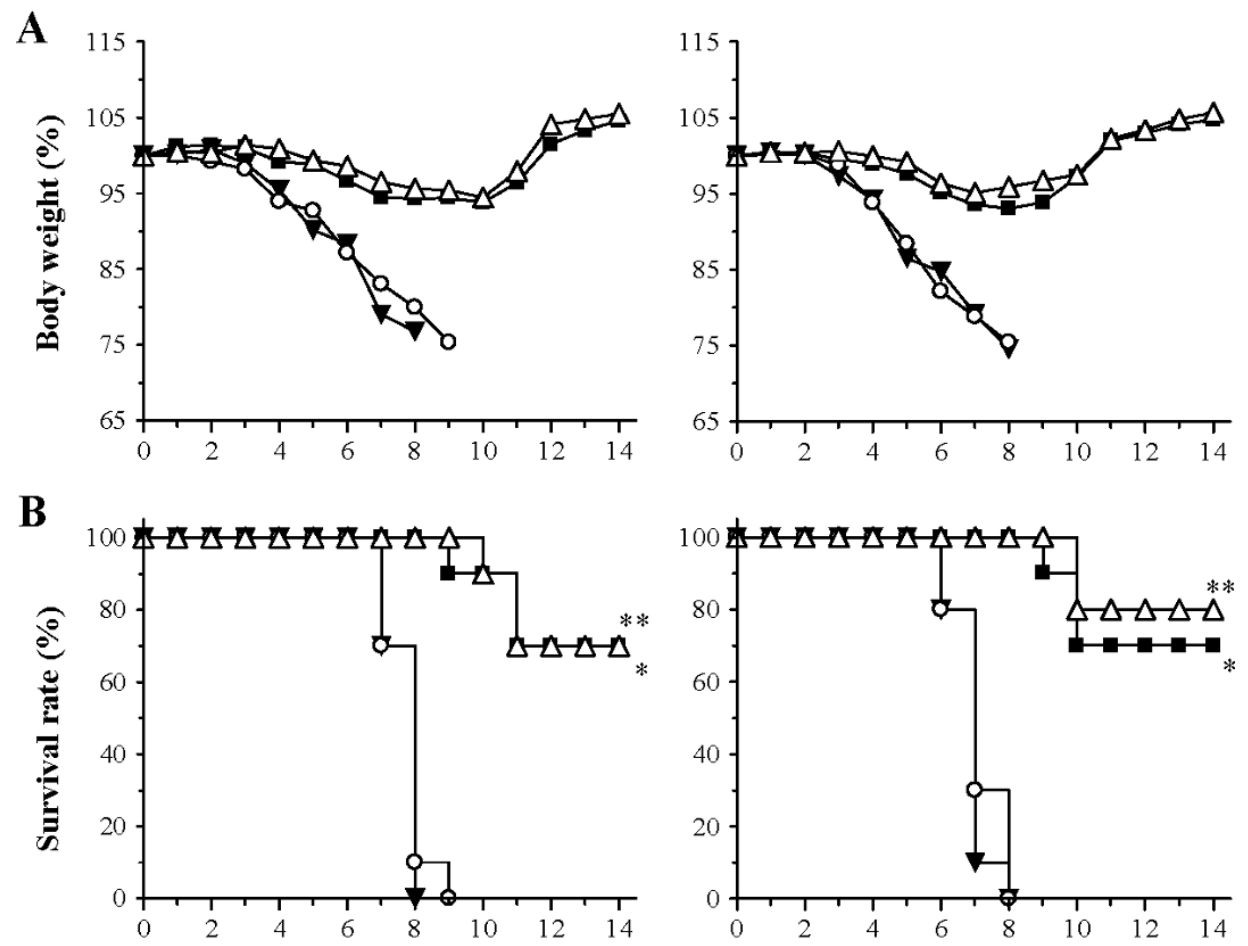

clade1: VN/1194

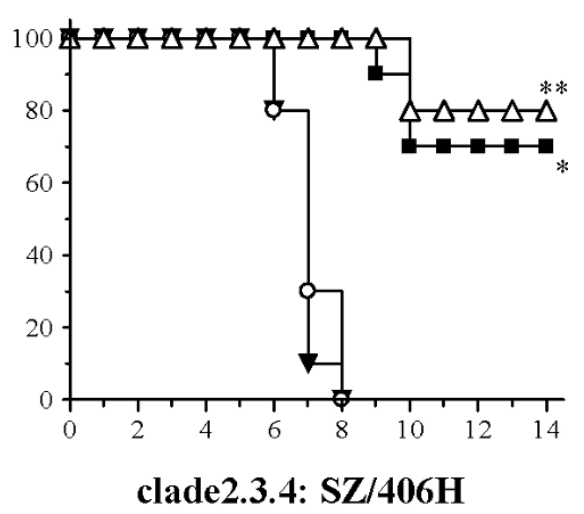

Days post-challenge

Figure 4 Weight loss and survival in lethal H5N1 virus challenged mice. Mice were challenged with 10LD 50 of H5N1 virus, clade1: VN/1194 or clade2.3.4: $\mathrm{SZ} / 406 \mathrm{H}$, and monitored daily for 2 weeks post-challenge. A. Percentage change (\%) of mouse body weight. Each point represents mean body weight of 10 mice per group. B. Survival rate. The significant differences $(P<0.0001)$ of M2e-MAP+FCA/FIA versus FCA/FIA and M2eMAP+alum versus alum are indicated as * and ${ }^{* *}$, respectively.

safety, the synthetic peptide-based M2e-MAP vaccine is superior to the DNA-, adenoviral vector-, and recombinant protein-based M2 vaccines. For example, DNA vaccines have the potential to integrate the viral genomes into human DNA, to develop autoimmunity, and to induce antibiotic resistance [29]. The recombinant protein-based vaccine may have contamination of endotoxin and other unwanted antigens from cell cultures [30]. In spite of a relatively higher cost of production, synthetic peptide-based vaccine can be rapidly designed and synthesized and more convenient for storage and transportation, making M2e-MAP vaccine a better choice for speed development of effective and safe vaccines to combat emerging influenza pandemic.

Based on the evidence of our findings, the approach of developing M2e-based vaccines with broad cross-protection is feasible. Some strategies, such as incorporation of appropriate adjuvants into the present MAP system, modification of the present M2e consensus sequences of $\mathrm{H} 5 \mathrm{~N} 1$ viruses as vaccine target, and/or selection of other M2e expression forms, might be helpful to achieve full cross-protection against lethal $\mathrm{H} 5 \mathrm{~N} 1$ virus infection. The effects of such approaches need to be determined in further studies. The data reported here support the concept of developing an M2e-based vaccine candidate that could provide cross-protection against divergent HPAI H5N1 viruses. Such vaccine based on the highly conserved target antigen of $\mathrm{H} 5 \mathrm{~N} 1$ viruses might be used in combination with current $\mathrm{H} 5 \mathrm{~N} 1$ influenza vaccines to enhance protection and to prevent a possible future human pandemic of $\mathrm{H} 5 \mathrm{~N} 1$ influenza.

\section{Conclusions}

In the present study, we synthesized tetra-branched M2e-MAP based on the M2e sequence of $\mathrm{H} 5 \mathrm{~N} 1$ virus. The M2e-MAP vaccine induced strong M2e-specific IgG antibody responses, being able to protect mice against lethal challenge of both clade1: VN/1194 and clade2.3.4: SZ/406H H5N1 viruses. Based on the evidence of our findings, the approach of developing M2ebased vaccine with broad cross-protection is feasible. The data reported here support the concept of 
developing an M2e-based vaccine that could provide cross-protection against divergent HPAI H5N1 viruses.

\section{Methods \\ Tetra-branched M2e multiple antigenic peptide (M2e- MAP)}

Tetra-branched M2e-MAP carrying four copies of M2e peptide of H5N1 virus strain VN/1194 was synthesized on [Fmoc-Lys(Fmoc) $]_{2}$-Lys-Cys(Acm)- $\beta$ Ala-Wang Resin (Advanced ChemTech, Louisville, Kentuchy, USA) on a $0.02 \mathrm{mM}$ scale using an Applied Biosystems model 433A peptide synthesizer. Cleavage of the peptide from the resin was performed by treatment with trifluoroacetic acid (TFA), DTT, water, and triisopropylsila (TIPS) in the ratio 88:5:5:2 (TFA/DTT/ $\mathrm{H}_{2} \mathrm{O} / \mathrm{TIPS}$ ). Crude peptide was purified by reversed phase high-performance liquid chromatography (RP-HPLC). The purified peptide was characterized by amino acid analysis and matrixassisted laser desorption ionization mass spectrometry (MALDI-MS). Figure 5 shows the composition and sequence of M2e-MAP.

Mice

Female BALB/c mice at 4-6 weeks were purchased from the Laboratory Animal Unit and housed in the animal facility of The University of Hong Kong following the approved animal care protocols. Mice were rested for 2 weeks before immunization. The animal study was approved by the Department of Health of Government of Hong Kong Special Administration Region, and University Animal Ethics Committee of The University of Hong Kong.

\section{Viruses}

HPAI H5N1 virus isolates used in this study were clade1: VN/1194 and clade2.3.4: SZ/406H. H5N1 viruses were grown in the allantoic cavities of 10-day-old embryonated chicken eggs. Virus-containing allantoic fluid was harvested and stored in aliquots at $-80^{\circ} \mathrm{C}$ until use. The $\mathrm{LD}_{50}$ of each virus stain was determined in mice after serial dilutions of the virus stock. All infectious experiments related to $\mathrm{H} 5 \mathrm{~N} 1$ viruses were performed in an approved biosafety level 3 (BSL-3) facility at The University of Hong Kong.

\section{Animal experiment}

Mice were subcutaneously (s.c.) prime vaccinated with M2e-MAP (10 $\mu \mathrm{g} /$ mouse) plus Freund's complete adjuvant (FCA, sigma) and boosted twice with the same amount of immunogen plus Freund's incomplete adjuvant (FIA, Sigma) at 3-week intervals. For parallel experiments, mice were also intramuscularly (i.m.) vaccinated with the same amount of M2e-MAP immunogens plus alum adjuvant (Sigma) at the same condition of the above. Mice injected with Freund's or alum adjuvant were used as the respective control. Mouse sera were collected before immunization and 10 days post-each vaccination for detection of antibody responses.

Two weeks post-last vaccination, mice were intraperitoneally (i.p.) anesthetized with ketamine-xylazine $(75 / 5$ $\mathrm{mg} / \mathrm{kg}$ ), and intranasally (i.n.) challenged with $10 \mathrm{LD}_{50}$ of clade1: VN/1194 or clade2.3.4: SZ/406H H5N1 virus stain. Infected mice were observed and weighed daily for 2 weeks. Lung tissues were collected from euthanized mice 5 days post-challenge for further virological test and histopathological analysis.

\section{ELISA}

The M2-specific IgG antibody in the vaccinated mouse sera was detected by ELISA as previously described [31] with some modifications. Briefly, 96-well microtiter plates were pre-coated with $5 \mu \mathrm{g} / \mathrm{ml}$ of M2e-MAP overnight at $4{ }^{\circ} \mathrm{C}$. After blocking with $3 \%$ BSA containing 0.05\% Tween-20 in PBS, serial diluted mouse sera were added to the plates, followed by adding HRP-conjugated rabbit anti-mouse IgG (1:2,000, Invitrogen, Carlsbad, $\mathrm{CA})$ for $1 \mathrm{~h}$ at $37^{\circ} \mathrm{C}$. Assay was developed using 3,3',5,5'tetramethylbenzidine (TMB) (Zymed, Carlsbad, CA),

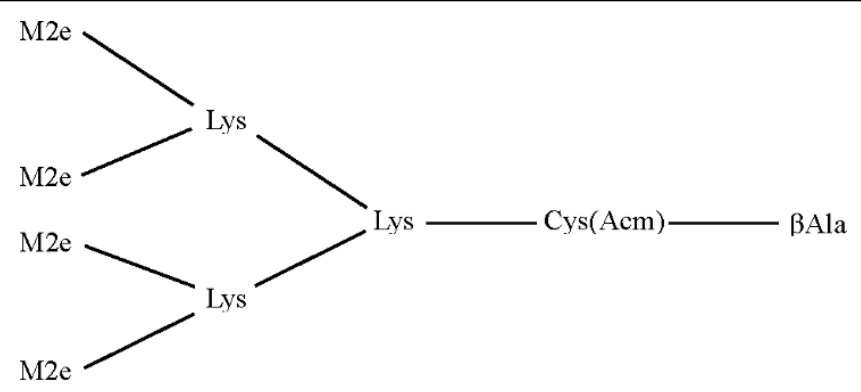

M2e=MSLLTEVETPTRNEWECRCSDSSD

Figure 5 Construction and sequence of M2e-MAP. The final form of M2e-MAP was synthesized on [Fmoc-Lys(Fmoc)]2-Lys-Cys(Acm)- $\beta$ AlaWang Resin in tetra-branched form, which carries four copies of M2e peptide. The sequence of M2e from highly pathogenic avian influenza H5N1 virus VN/1194 strain is shown at the bottom. 
and the reaction was stopped by adding $1 \mathrm{~N} \mathrm{H}_{2} \mathrm{SO}_{4}$. The absorbance at $450 \mathrm{~nm}$ was measured by an ELISA plate reader (Sunrise ${ }^{\mathrm{Tw}}$ microplate reader, TECAN, NC).

\section{Virus titers in lung tissues}

Lung tissues from euthanized mice were aseptically removed and homogenized in minimal essential medium (MEM) plus antibiotics to achieve $10 \%(\mathrm{w} / \mathrm{v})$ suspensions of lungs. Ten-fold serial dilutions of samples were added in quadruplicate to the monolayer of MadinDarby canine kidney (MDCK) cells seeded at 96-well cell culture plates $12 \mathrm{~h}$ before infection, and allowed to absorb for $2 \mathrm{~h}$ at $37^{\circ} \mathrm{C}$. Fresh medium was then added to the cells and continued to incubate for $72 \mathrm{~h}$. Virus cytopathic effect $(\mathrm{CPE})$ was observed daily and the viral titer was determined by the hemagglutinin (HA) test indicated as follows. Fifty microlitre of $0.5 \%$ turkey red blood cells (Lampire Biological Laboratories, Pipersville, PA) was added to $50 \mu \mathrm{l}$ of cell culture supernatant and incubated at room temperature for $30 \mathrm{~min}$. Wells containing HA were scored as positive. The virus titer was calculated by the Reed and Muench method and expressed as $\log _{10} \mathrm{TCID}_{50} / \mathrm{g}$ of lung tissues.

\section{Histopathological analysis}

The lung tissues of challenged mice were immediately fixed in $10 \%$ neutral buffered formalin and embedded in paraffin wax. Sections were made at 4-6 $\mu \mathrm{m}$ thickness and mounted on slides. Histopathological changes were examined by $H \& E$ staining and observed under light microscopy as previously described [32].

\section{Statistical analysis}

The significance between survival curves was analyzed by Kaplan-Meier survival analysis with log-rank test. Other data were analyzed using the 2-tailed Student's $t$ test. $P<0.0001$ was considered significant. All analyses were performed in Graphpad Prism software.

\section{Abbreviations \\ HPAl: highly pathogenic avian influenza; M2e-MAP: M2e-based multiple antigenic peptide; FCA: Freunds' complete adjuvant; FIA: Freunds' incomplete adjuvant; VN/1194: ANietnam/1194/2004(H5N1); SZ/406H: A/ Shenzhen/406H/2006(H5N1); LD 50 : 50\% lethal dose; $\log _{10} T_{C I D} / g$ : $\log _{10}$ $50 \%$ tissue-culture infectious dose per gram.}

\section{Acknowledgements}

This study was supported by the National High Technology R\&D Program of China (863 Program, No. 2006AA02Z406), National Basic Research Program of China (973 Program, No. 2005CB523001), National Natural Science Foundation of China (30901371), Mega-projects of Science Research for the 11th Five-Year Plan (2009ZX10004-4001), the Area of Excellence Scheme of the University Grants Committee (Grant AoE/M-12/06) and Research Fund for the Control of Infectious Diseases (09080812), Hong Kong SAR.

\section{Author details}

'State Key Laboratory of Pathogen and Biosecurity, Beijing Institute of Microbiology and Epidemiology, Beijing 100071, China. ${ }^{2}$ Department of Microbiology, The University of Hong Kong, Hong Kong, China. ${ }^{3}$ Lindsley F Kimball Research Institute, New York Blood Center, New York, NY 10065, USA

\section{Authors' contributions}

GZ, BZ and YZ designed research. GZ, YL, JG, SS, HS and CC performed research. GZ, SS, ZK and YG analyzed data. GZ, LD, SJ, BZ and YZ wrote and modified the paper. All authors read and approved the final manuscript.

\section{Competing interests}

The authors declare that they have no competing interests.

Received: 14 October 2009

Accepted: 18 January 2010 Published: 18 January 2010

\section{References}

1. Cumulative Number of Confirmed Human Cases of Avian Influenza A/ (H5N1) Reported to WHO. http://www.who.int/csr/disease/avian_influenza/ country/cases_table_2009_09_24/en/index.html.

2. Kuiken T, Holmes EC, McCauley J, Rimmelzwaan GF, Williams CS, Grenfell BT: Host species barriers to influenza virus infections. Science 2006, 312:394-397.

3. Horimoto T, Kawaoka Y: Influenza: lessons from past pandemics, warnings from current incidents. Nat Rev Microbiol 2005, 3:591-600

4. Sugrue RJ, Hay AJ: Structural characteristics of the M2 protein of influenza A viruses: evidence that it forms a tetrameric channel. Virology 1991, 180:617-624

5. Holsinger $\amalg$, Lamb RA: Influenza virus $M 2$ integral membrane protein is a homotetramer stabilized by formation of disulfide bonds. Virology 1991, 183:32-43

6. Fiers W, De Filette M, Birkett A, Neirynck S, Min Jou W: A "universal" human influenza A vaccine. Virus Res 2004, 103:173-176.

7. Zebedee SL, Lamb RA: Influenza A virus M2 protein: monoclonal antibody restriction of virus growth and detection of $\mathrm{M} 2$ in virions. Virol 1988, 62:2762-2772.

8. Liu W, Zou P, Chen YH: Monoclonal antibodies recognizing EVETPIRN epitope of influenza A virus M2 protein could protect mice from lethal influenza A virus challenge. Immunol Lett 2004, 93:131-136.

9. Slepushkin VA, Katz JM, Black RA, Gamble WC, Rota PA, Cox NJ: Protection of mice against influenza $A$ virus challenge by vaccination with baculovirus-expressed M2 protein. Vaccine 1995, 13:1399-1402

10. Neirynck S, Deroo T, Saelens X, Vanlandschoot P, Jou WM, Fiers W: A universal influenza $A$ vaccine based on the extracellular domain of the M2 protein. Nat Med 1999, 5:1157-1163.

11. Fan J, Liang X, Horton MS, Perry HC, Citron MP, Heidecker GJ, Fu TM, Joyce J, Przysiecki CT, Keller PM, Garsky VM, Ionescu R, Rippeon Y, Shi L, Chastain MA, Condra JH, Davies ME, Liao J, Emini EA, Shiver JW: Preclinical study of influenza virus A M2 peptide conjugate vaccines in mice, ferrets, and rhesus monkeys. Vaccine 2004, 22:2993-3003.

12. Tompkins SM, Zhao ZS, Lo CY, Misplon JA, Liu T, Ye Z, Hogan RJ, Wu Z Benton KA, Tumpey TM, Epstein SL: Matrix protein 2 vaccination and protection against influenza viruses, including subtype H5N1. Emerg Infect Dis 2007, 13:426-435.

13. Mozdzanowska K, Feng J, Eid M, Kragol G, Cudic M, Otvos L Jr, Gerhard W: Induction of influenza type A virus-specific resistance by immunization of mice with a synthetic multiple antigenic peptide vaccine that contains ectodomains of matrix protein 2. Vaccine 2003, 21:2616-2626.

14. Tam JP: Synthetic peptide vaccine design: synthesis and properties of a high-density multiple antigenic peptide system. Proc Natl Acad Sci USA 1988, 85:5409-5413.

15. Posnett DN, McGrath H, Tam JP: A novel method for producing antipeptide antibodies. Production of site-specific antibodies to the T cell antigen receptor beta-chain. J Biol Chem 1988, 263:1719-1725.

16. Wang CY, Looney DJ, Li ML, Walfield AM, Ye J, Hosein B, Tam JP, WongStaal F: Long-term high-titer neutralizing activity induced by octameric synthetic HIV-1 antigen. Science 1991, 254:285-288.

17. Mozdzanowska K, Zharikova D, Cudic M, Otvos L, Gerhard W: Roles of adjuvant and route of vaccination in antibody response and protection engendered by a synthetic matrix protein 2-based influenza $A$ virus vaccine in the mouse. Virol J 2007, 4:118.

18. Li KS, Guan Y, Wang J, Smith GJ, Xu KM, Duan L, Rahardjo AP, Puthavathana P, Buranathai C, Nguyen TD, Estoepangestie AT, Chaisingh A, Auewarakul P, Long HT, Hanh NT, Webby RJ, Poon LL, Chen H, Shortridge KF, Yuen KY, Webster RG, Peiris JS: Genesis of a highly 
pathogenic and potentially pandemic $\mathrm{H} 5 \mathrm{~N} 1$ influenza virus in eastern Asia. Nature 2004, 430:209-213.

19. Smith GJ, Fan XH, Wang J, Li KS, Qin K, Zhang JX, Vijaykrishna D, Cheung CL, Huang K, Rayner JM, Peiris JS, Chen H, Webster RG, Guan Y, et al: Emergence and predominance of an $\mathrm{H} 5 \mathrm{~N} 1$ influenza variant in China. Proc Natl Acad Sci USA 2006, 103:16936-16941.

20. Chen H, Smith GJ, Li KS, Wang J, Fan XH, Rayner JM, Vijaykrishna D, Zhang JX, Zhang LJ, Guo CT, Cheung CL, Xu KM, Duan L, Huang K, Qin K, Leung YH, Wu WL, Lu HR, Chen Y, Xia NS, Naipospos TS, Yuen KY, Hassan SS, Bahri S, Nguyen TD, Webster RG, Peiris JS, Guan Y: Establishment of multiple sublineages of H5N1 influenza virus in Asia: implications for pandemic control. Proc Natl Acad Sci USA 2006, 103:2845-2850.

21. Yang ZY, Wei CJ, Kong WP, Wu L, Xu L, Smith DF, Nabel GJ: Immunization by avian $\mathrm{H} 5$ influenza hemagglutinin mutants with altered receptor binding specificity. Science 2007, 317:825-828.

22. Webster RG, Peiris M, Chen H, Guan Y: H5N1 outbreaks and enzootic influenza. Emerg Infect Dis 2006, 12:3-8.

23. Liu W, Zou P, Ding J, Lu Y, Chen YH: Sequence comparison between the extracellular domain of $\mathrm{M} 2$ protein human and avian influenza A virus provides new information for bivalent influenza vaccine design. Microbes Infect 2005, 7:171-177.

24. Jegerlehner A, Schmitz N, Storni T, Bachmann MF: Influenza A vaccine based on the extracellular domain of M2: weak protection mediated via antibody-dependent NK cell activity. J Immunol 2004, 172:5598-5605.

25. Wang R, Song A, Levin J, Dennis D, Zhang NJ, Yoshida H, Koriazova L, Madura L, Shapiro L, Matsumoto A, Yoshida H, Mikayama T, Kubo RT, Sarawar S, Cheroutre $H$, Kato S: Therapeutic potential of a fully human monoclonal antibody against influenza A virus M2 protein. Antiviral Res 2008, 80:168-177.

26. Boltz DA, Douangngeun $B$, Sinthasak $S$, Phommachanh $P$, Rolston $S$, Chen H, Guan Y, Peiris JS, Smith JG, Webster RG: H5N1 influenza viruses in Lao People's Democratic Republic. Emerg Infect Dis 2006, 12:1593-1595.

27. Chutinimitkul S, Songserm T, Amonsin A, Payungporn S, Suwannakarn K Damrongwatanapokin S, Chaisingh A, Nuansrichay B, Chieochansin T, Theamboonlers A, Poovorawan Y: New strain of influenza A virus (H5N1), Thailand. Emerg Infect Dis 2007, 13:506-507.

28. Antigenic and genetic characteristics of $\mathrm{H} 5 \mathrm{~N} 1$ viruses and candidate vaccine viruses developed for potential use in humanvaccines. http:// www.who.int/csr/disease/avian_influenza/guidelines/h5n1virus/en/index. html.

29. Kutzler MA, Weiner DB: DNA vaccines: ready for prime time?. Nat Rev Genet 2008, 9:776-788.

30. Wakelin SJ, Sabroe I, Gregory CD, Poxton IR, Forsythe IL, Garden OJ, Howie SE: "Dirty little secrets"-endotoxin contamination of recombinant proteins. Immunol Lett 2006, 106:1-7.

31. Du L, Zhao G, He Y, Guo Y, Zheng BJ, Jiang S, Zhou Y: Receptor-binding domain of SARS-CoV spike protein induces long-term protective immunity in an animal model. Vaccine 2007, 25:2832-2838.

32. Du L, Zhao G, Lin Y, Sui H, Chan C, Ma S, He Y, Jiang S, Wu C, Yuen KY, Jin DY, Zhou Y, Zheng BJ: Intranasal vaccination of recombinant adenoassociated virus encoding receptor-binding domain of severe acute respiratory syndrome coronavirus (SARS-CoV) spike protein induces strong mucosal immune responses and provides long-term protection against SARS-CoV infection. J Immunol 2008, 180:948-956.

Publish with BioMed Central and every scientist can read your work free of charge

"BioMed Central will be the most significant development for disseminating the results of biomedical research in our lifetime. "

Sir Paul Nurse, Cancer Research UK

Your research papers will be:

- available free of charge to the entire biomedical community

- peer reviewed and published immediately upon acceptance

- cited in PubMed and archived on PubMed Central

- yours - you keep the copyright 